\title{
A METÁFORA DA CIÊNCIA COMO JOGO EM KUHN
}

\author{
The metaphor of science as a game in Kuhn
}

\section{Elizabeth de Assis Dias}

Resumo: O objetivo do presente trabalho é analisar, por meio da metáfora do jogo de quebra-cabeçs, o caráter da ciência no pensamento de Kuhn. Pretendemos mostrar que, além dos aspectos históricos e psicossociais que se destacam como a grande novidade de sua abordagem, há uma outra que emerge da prática da ciência nomal, cujo enfoque, destoa da tradição. Trata-se da ênfase que ele dá a própria atividade de investigação da ciência, mais precisamente ao caráter dos problemas a serem pesquisados e a forma de solucioná-los.

Palavras-chave: Quebra-Cabeç, Regras, Resolução de Problemas, Exemplar, Analogia

Abstract: The aim of the present paper is to analyze, through the puzzle-solving metaphor, the character of science in Kuhn's thought. We intend to show that, in addition to the historical and psychosocial aspects that stand out as the great novelty of its approach, there is another that emerges from the practice of normal science, whose focus, unlike tradition. It is the emphasis that it gives the very activity of research of science, more precisely the character of the problems to be researched and how to solve them

Keywords: Puzzle-Solving, Rules, Solubility of Problems, Exemplars, Analogie.

\section{Introdução}

O uso de metáforas tem sido muito recorrente na concepção de diversos filósofos da ciência para esclarecer a natureza da ciência, o caráter das teorias, o progresso científico em termos evolutivos ou revolucionários e para estabelecer distinções entre a posição que defendem face a de outros filósofos.

A obra de Kuhn é rica em metáforas, que nos possibilitam elucidar vários aspectos que sua teoria da ciência envolve. Uma analogia muito recorrente é a figura do pato-coelho da Gestalt, que serve tanto para ilustrar suas divergências com Popper, ao destacar que eles têm olhares distintos sobre a ciência e nesse sentido onde um vê pato outro vê coelho' como também, para definir o que ocorre com as revoluções cientificas, quando um paradigma é substituído por outro, ocasionando uma mudança da forma

${ }^{1}$ KUHN, T. "Lógica da descoberta ou psicologia da pesquisa?". In LAKATOS, I. E MUSGRAVE, A. A critica e o desenvolvimento do conhecimento. São Paulo: Editora Cultrix, 1979, p.8 
perceptiva, assim, o que era visto antes como pato, com o novo paradigma passa a ser visto como coelho ${ }^{2}$, uma outra analogia identifica a ciência com o jogo de quebra-cabeça (puzzle), pondo em evidência toda uma estrutura paradigmática que direciona as pesquisas e o caráter dos problemas que são pesquisados; há também, a similaridade entre a experiência psicológica com as cartas de baralho anômalas - na qual alguns sujeitos tiveram dificuldades de identificar tais cartas ao lhes serem apresentadas em sequências - com a situação dos cientistas que têm dificuldades em reconhecer a descoberta de novidades no âmbito de suas pesquisas, visto que foram educados em uma determinada tradição paradigmática ${ }^{3}$. Uma outra analogia estabelece relações entre o trabalho do carpinteiro e o do cientista normal, nesta é enfatizado que assim como o carpinteiro não pode culpar suas ferramentas pelo mau trabalho executado, o cientista normal não pode culpar o paradigma quando fracassa em solucionar um problema de ciência normal, visto que este tem uma solução assegurada pelo paradigma ${ }^{4}$. E há ainda a analogia que associa a evolução dos organismos com a evolução das teorias científicas ${ }^{5}$. Enfim, são muitas as metáforas que Kuhn se utiliza, mas, neste trabalho interessa-nos uma em particular a que compara a ciência com o jogo de quebra-cabeças.

Ao tratar dessa analogia iremos tomar como objeto de nossa análise a ciência normal, pois esta se mostra tão fundamental no pensamento do filósofo, que muito embora não seja sua preocupação demarcar o discurso científico, ele considera que a mesma nos possibilita distinguir a ciência de outras atividades criativas ${ }^{6}$. Contrapondose a Popper que ignora a ciência normal ao definir seu critério de demarcação, admite que se existe um tal critério ele está na pesquisa de ciência normal ${ }^{7}$. E, é justamente para definir a natureza dessa ciência que ele se utiliza da metáfora do jogo de quebra-cabeça ${ }^{8}$ (puzzle). Mas, essa não é a única analogia que ele relaciona a ciência com o jogo, algumas vezes se refere ao jogo de palavras cruzadas (crossword puzzles) e ao jogo de xadrez (chess puzzle) $)^{9}$. Mas, a metáfora mais recorrente é com o jogo de quebra-cabeça. A questão que se coloca é a seguinte: como entender a prática da ciência como um jogo? O que haveria de comum entre essas duas atividades que aparentemente se mostram tão distintas?

Popper, que também se utilizou dessa metáfora para esclarecer o caráter da ciência, vê a similaridade entre a ciência e o jogo da perspectiva das regras metodológicas. Diz ele: "Assim como o xadrez pode ser definido em função de regras que lhes são próprias, a Ciência pode ser definida por meio de regras metodológicas. ${ }^{" 10}$. Nesse sentido, a ciência seria uma prática norteada por regras aceitas pelos cientistas.

Kulhn, muito embora reconheça em sua analogia, a existência de regras no âmbito da pesquisa de ciência normal não as considera como guias explícitos de ação e nem tampouco, como definidoras do caráter da ciência. Ele procura mostrar com a metáfora do jogo, uma nova maneira de se conceber a prática da ciência, tendo como foco o próprio processo de investigação e não os procedimentos metodológicos que o norteiam.

Esse novo ollhar sobre a ciência tem sido pouco percebido pelos estudiosos de sua obra, que se preocuparam em destacar como novidade de sua abordagem os fatores históricos e psicossociais inerentes à prática cientifica. Ransanz, a este respeito, assinala

\footnotetext{
${ }^{2}$ KUHN, T. A Estrutura das revoluçôes científicas. São Paulo: Editora Perspectiva, 1975, p. 116/117

${ }^{3}$ KUHN, T. A Estrutura das revoluções científicas. São Paulo: Editora Perspectiva, 1975, p. 89/90

${ }^{4}$ KUHN, T. A Estrutura das revoluções científicas. São Paulo: Editora Perspectiva, 1975, p. 110/111

${ }^{5}$ KUHN, T. A Estrutura das revoluções científicas. São Paulo: Editora Perspectiva, 1975, p. 214

${ }^{6}$ KUHN, T. "Lógica da descoberta ou psicologia da pesquisa?". In LAKATOS, I. E MUSGRAVE, A. A critica e o desenvolvimento do conhecimento. São Paulo: Editora Cultrix, 1979. 1979, p.9

${ }^{7}$ KUHN, T. "Lógica da descoberta ou psicologia da pesquisa?". In LAKATOS, I. E MUSGRAVE, A. A critica eo desenvolvimento do conhecimento. São Paulo: Editora Cultrix, 1979. 1979, p.11

${ }^{8}$ Iremos utilizar a tradução de puzzle como quebra-cabeça porque consideramos que reflete melhor a novidade da concepcão de Kuhn que pretendemos apresentar neste texto.

${ }^{9}$ KUHN, T. A tensão essencial. São Paulo: Ed. da Unesp, 2011, p. 288, nota 7

${ }^{10}$ POPPER, K. A logica da pesquisa científica. São Paulo: Cultrix, 1972, p.56
} 
que a epistemologia tradicional se caracterizou por sua preocupação metodológica tendo em vista definir um método que garantisse a racionalidade cientifica, enquanto que a nova filosofia da ciência de Kuhn se voltou para a análise histórica da prática cientifica ${ }^{11}$.

Nossa pretensão, neste trabalho, é assim, mostrar por meio da metáfora do jogo, que além dos aspectos ressaltados pelos estudiosos de KKuhn, há uma outra novidade que emerge de sua obra ao tratar da prática da ciência normal, cujo enfoque, destoa da tradição. Trata-se da ênfase que ele dá a atividade de investigação, mais precisamente ao caráter dos problemas a serem pesquisados e na forma de solucioná-los.

\section{A novidade da analogia da ciência normal com o jogo de quebra cabeças}

A metáfora da ciência normal com o jogo de quebra-cabeça, na concepção de Kulhn, tem um papel importante, na medida em que nos possibilitar ter uma melhor compreensão da nova concepção de ciência, que emerge de sua obra. Neste sentido, a ciência, dita "normal", tal como Kulhn a entende, é uma atividade que tem características bastante distintas das que foram definidas pela tradição epistemológica, que considerava a ciência empírica como um sistema de teorias, constituída de uma estrutura lógico-linguística própria ${ }^{12}$.

O novo olhar de Kuhn sobre a ciência, da perspectiva do jogo de quebra-cabeça, põe em destaque não as teorias e sua estrutura lógico-metodológica, mas os problemas. Tal ideia fica bastante evidente na própria noção de quebra-cabeças, que em seu sentido usual denota uma atividade que demanda a solução de problemas que desafiam a nossa engenhosidade ${ }^{13}$.

A resolução de problemas parece ser, assim, o aspecto central que relaciona a ciência normal com este tipo de jogo. Em sua obra $A$ estrutura das revoluções científicas, mais precisamente no terceiro capítulo, intitulado "A ciência normal como resolução de quebra-cabeças", Kuhn deixa evidente não somente que a ciência normal se define por essa prática, como também, que seus problemas são similares aos quebra-cabeças.

Com efeito, Popper também concebe como função da ciência a solução de problemas ${ }^{14}$. Mas, o seu enfoque não está propriamente nos problemas e sim nas teorias que são propostas para solucioná-los. Para ele, os problemas são o ponto de partida da ciência, mas eles afloram quando nossas teorias apresentam dificuldades ou contradições e deste modo conduzem o cientista na descoberta de novas teorias. Diz ele:

O conhecimento não começa de percepções ou observações ou de coleção de fatos ou números, porém, começa, mais propriamente, de problemas [.... ]. Pois cada problema surge da descoberta de que algo não está em ordem com nosso suposto conhecimento; ou, examinado logicamente, da descoberta de uma contradição interna entre nosso suposto conhecimento e os fatos; ou, declarado talvez mais corretamente, da descoberta de uma contradição aparente entre nosso suposto conhecimento e os supostos fatos. ${ }^{15}$

A novidade da abordagem de Kuhn, não está em conceber a ciência como "uma atividade de resolução de problemas"16, conforme afirmam alguns de seus comentadores, pois Popper, antes dele, já havia considerado a ciência dessa perspectiva. A inovação, em sua concepção, está no caráter desses problemas e na forma como os cientistas os solucionam. Kuhn deixa claro esta diferença de enfoque quando afirma: "É importante

\footnotetext{
${ }^{11}$ RANSANZ, A.R.P. Kuhn y el cambio científico. 1a ed. México: Fondo de Cultura económica, 1999, p.15

${ }^{12}$ POPPER, K. A lógica da pesquisa científica. São Paulo: Cultrix, 1972, p.61

${ }^{13}$ KUHN, T. A Estrutura das revoluções científicas. São Paulo: Editora Perspectiva, 1975, p.59

${ }^{14}$ POPPER, K. Conjecturas e refutações. 2a ed. Brasília: Ed. da Universidade de Brasília, 1982, p.95

${ }^{15}$ POPPER, K. Lógica das Ciências socials. Rio de Janeiro: Tempo brasileiro, 1978, p.14/15

${ }^{16}$ ABRANTES, P.C. Método e ciência: una abordagem filosófica 2o ed. Belo Horizonte/MG: Fino Traço, 2014, p. 200 , nota 5
} 
notar que, quando descrevo o cientista como solucionador de quebra-cabeças e Sir Karl o descreve como um solucionador de problemas [...], a similaridade de nossos termos disfarça uma divergência fundamental" ${ }^{17}$

Olhando a ciência dessa nova perspectiva de Kulhn podemos dizer, de antemão, que a preocupação de Kuhn está voltada para o caráter dos problemas que os cientistas pesquisam e para a forma como solucionam esses problemas.

Assim, a analogia da ciência com o jogo trás a tona duas novidade da abordagem de Kuhn: a primeira está em considerar os problemas que a ciência busca solucionar como similares aos quebra-cabeças. $\mathbb{E}$ a segunda, diz respeito à forma como os cientistas solucionam estes problemas, guiados por exemplares e não por regras metodológicas. Porém, isto não significa dizer, que não há regras que orientem suas atividades, conforme iremos mostrar, mas sim que estas estão pressupostas quando os cientistas tentam solucionar os problemas tendo por base as soluções padrões.

\section{Os problemas da ciência normal como quebra-cabeças}

Os problemas de ciência normal, tal como os quebra-cabeças, se definem como problemas que têm um caráter peculiar, no sentido de que são passíveis de serem solucionados. Nesse sentido, não é qualquer problema que se configura como objeto de pesquisa da ciência normal. Há problemas bastante prementes e relevantes que afligem a humanidade hoje e que não podem ser considerados como problemas de estudo da ciência normal, como a busca da cura do câncer ou do Alzheimer, a eliminação da violência e da corrupção nas sociedades. Tais problemas não possuem padrões de solução assegurados.

Deste modo, Kuhn procura definir um critério para se determinar se um problema é científico ou não, ou seja, se é um problema de ciência normal. Este critério é ditado pelos padrões de solução disponível para elucidá-lo e, enquanto, estiver em voga, podemos dizer que os problemas são solucionados por ele.

Mas, além da solução assegurada, há um outro critério que define o caráter dos problemas de ciência normal, trata-se de problemas que desafiam as habilidades do cientista, por isso, os cientistas sentem-se motivados a solucioná-los.

Kuhn chama atenção, assim, para o aspecto motivacional dos cientistas face aos problemas que enfrentam. Como explicar o entusiasmo e a dedicação que os cientistas demonstram por estes problemas? Tal como no jogo de quebra-cabeça, o que desafia o cientista normal a empreender sua pesquisa não é nenlhum fim pragmático exterior a sua própria prática. "O critério que estabelece a qualidade de um bom quebra-cabeça nada tem a ver com o fato de seu resultado ser intrinsicamente interessante ou importante ${ }^{p 18}$. Muitos problemas considerados como relevantes não se caracterizam como quebracabeças, na medida em que não possuem um padrão de solução assegurado. Assim, a motivação do cientista normal, tal como a do jogador de quebra-cabeças, advém do fato que há uma solução bem-sucedida para o problema com o qual se defronta. Chegar a esta solução só depende de sua habilidade. "O que o incita ao trabalho é a convicção de que, se for suficientemente habilidoso, conseguirá solucionar um quebra-cabeça que ninguém até então resolveu ou, pelo menos, não resolveu tão bem"119. Assim, o cientista é desafiado a provar a sua própria capacidade de solucionar problemas tendo por base os padrões aceitos pela comunidade cientifica especializada da qual faz parte.

Mas, esses critérios muito embora se mostrem relevantes para definir os problemas de ciência normal, eles não parecem ser suficientes. Podemos dizer que, além de "possuir uma solução assegurada" e desafiar as habilidades do cientista, um problema

${ }^{17}$ KUHN, T. "Lógica da descoberta ou psicologia da pesquisa?". In LAKATOS, I. E MUSGRAVE, A. A crítica e o desenvolvimento do conhecimento. São Paulo: Editora Cultrix, 1979, p. 9/10, nota7.

${ }^{18}$ KUHN, T. A Estrutura das revoluções científicas. São Paulo: Editora Perspectiva, 1975, p. 59.

${ }^{19}$ KUHN, T. A Estrutura das revoluçōes científicas. São Paulo: Editora Perspectiva, 1975, p.61 
de ciência normal tal como os quebra-cabeças deve estar sujeito a regras que estabelecem limites no que diz respeito às soluções que podem ser aceitas e aos procedimentos para obtê-las ${ }^{20}$. Nesse sentido, as regras parecem ter um papel importante na resolução dos problemas. Vejamos então, como se dá a resolução dos problemas e o papel que estas regras desempenham nesse processo.

${ }^{20}$ KUHN, T. A Estrutura das revoluções cientificas. São Paulo: Editora Perspectiva, 1975, p. 61 


\section{A forma como os cientistas procedem para solucionar os problemas de ciência normal}

Diferentemente, da tradição epistemológica, que estipulou cânones metodológicos para nortear os cientistas em suas pesquisas, Kuhn não se preocupou em definir tais procedimentos para os cientistas solucionarem os problemas de ciência normal. Mas, isto não significa dizer que a resolução desses problemas fica ao sabor das idiossincrasias dos cientistas. Admite que existem regras que norteiam a forma de abordar esses problemas e que, definem, também, os parâmetros para as soluções aceitáveis. Mas, deixa claro que estas regras são tomadas em um sentido amplo, trata-se de "compromissos que os cientistas derivam de seus paradigmas"21.

Hoyningen-Huene esclarece que tais "regras" não são "guias explícitos de ação, sejam elas condicionais ou absolutas", funcionam mais como "regulamentações" que restringem os caprichos do pesquisador e muitas delas são dadas implicitamente, na forma de soluções exemplares de problemas ${ }^{22}$. Podemos dizer que tais regulamentações, visam estabelecer certas restrições ao cientista de modo a garantir a solução dos problemas de ciência normal.

Kuthn distingue quatro categorias de "regras" que operam no âmbito da ciência normal. A primeira, mais evidente e também, a mais coercitiva, a qual os cientistas aderem, diz respeito a enunciados gerais que expressam explicitamente leis, conceitos e teorias científicas ${ }^{23}$. A segunda, refere-se aos instrumentos empregados nas pesquisas, trata-se "compromissos relativos a tipos de instrumentos preferidos e as maneiras adequadas para utilizá-los"24. A terceira categoria de "regras" diz respeito aos compromissos de "caráter quase metafisico" referentes a pressupostos acerca da natureza do universo e da forma de explicar os fenômenos tendo em vista esses pressupostos. Esses compromissos, além da dimensão metafísica, possuem também, uma dimensão metodológica, na medida em que indicam como deve ser a natureza das leis fundamentais, as explicações aceitáveis e os problemas a serem pesquisados ${ }^{25}$. $\mathbb{E}_{\text {, }}$ por fim, o quarto tipo de "regra" concerne aos compromissos que definem a própria atividade desenvolvida como ciência. Nesse sentido, o cientista, ao desenvolver suas pesquisas, deve estar comprometido em obter uma compreensão do mundo e em ampliar a precisão e o alcance das teorias que dispõe acerca do mesmo. Para tal deve investigar rigorosamente algum aspecto da natureza e se esta lhe revelar certos fenômenos que não se encaixam em sua teoria deverá procurar refinar suas técnicas de observação, ou então, articular as mesmas ${ }^{26}$.

Esses compromissos conceituais, teóricos, metodológicos e instrumentais proporcionam aos cientistas as "regras" que lhes possibilitam ter uma compreensão do mundo e de sua própria prática e, assim, podem dedicar-se aos problemas especializados tendo por referência o que tais regras lhes indicam, como também, levando em conta os conhecimentos que dispõe.

Mas, embora Kulhn reconheça a existência destas regras, não as considera como suficientes para definir a prática da ciência normal na resolução de problemas, pois esta não é totalmente guiada por regras explicitas. Diz ele:

Embora obviamente existam regras às quais todos os praticantes de uma especialidade científica aderem em um determinado momento, essas regras não podem por si mesmas especificar tudo aquilo que a prática desses especialistas

\footnotetext{
${ }^{21}$ KUHN, T. A Estrutura das revolucoes cientificas. São Paulo: Editora Perspectiva, 1975, p. 63

22 HUENE-HOYNINGEN, P. Reconstructing scientific revolutions. Chicago e London: The University of Chicago press, 1993, p.173

${ }^{23}$ KUHN, T. A Estrutura das revoluçoes científicas. São Paulo: Editora Perspectiva, 1975, p. 63

24 KUHN, T. A Estrutura das revoluçes científicas. São Paulo: Editora Perspectiva, 1975, p. 64

${ }^{25} \mathrm{KUHN}, \mathrm{T}$. A Estrutura das revoluçōes científicas. São Paulo: Editora Perspectiva, 1975, p. 65

${ }^{26}$ KUHN, T. A Estrutura das revoluçơes científicas. São Paulo: Editora Perspectiva, 1975, p.65
} 
tem em comum. A ciência normal é uma atividade altamente determinada, mas não precisa ser inteiramente determinada por regras ${ }^{27}$.

Deste modo, Kulhn admite que o jogo da ciência envolve outros elementos além das regras. Um elemento central é o paradigma, uma vez que as próprias regras derivam dele. Deste modo, o paradigma pode direcionar as pesquisas mesmo quando tais regras não se fizerem presentes ${ }^{28}$.

Com efeito, no âmbito de um paradigma, que Kuhn passou a denominar, a partir do Posfácio de 1969, de matriz disciplinar, encontram-se os principais elementos para o trabalho cognitivo da pesquisa de ciência normal, com os quais os cientistas estão comprometidos, a saber. as generalizações simbólicas (leis ou princípios fundamentais de uma teoria); os compromissos ontológicos (expressos nos modelos que os cientistas utilizam para representar seu campo de estudo); os valores e os exemplares ${ }^{29}$. Esses elementos parecem corresponder às quatro categorias de regras que analisamos acima, que operam no âmbito da ciência normal.

Mas, o interesse fundamental de Kuhn é por um dos elementos desta constelação de compromissos dos cientistas, os exemplares, isto é, as "soluções concretas de problemas", que quando tomadas como exemplos podem substituir as regras que orientam a pesquisa de ciência normal ${ }^{30}$. Os exemplares constituem o sentido estrito do termo paradigma e, no jogo da ciência, desempenham um papel primordial, na medida em que é com base neles que os cientistas resolvem outros problemas similares.

Kuhn atribui aos exemplares prioridades em relação às próprias regras que norteiam a ciência e assim, pretende opor-se a forma como os filósofos da ciência procuravam defini-la tendo por base teorias e regras metodológicas, relegando os problemas de aplicação a um segundo plano, pois estes são vistos apenas como meios para que o estudante de uma ciência assimile aquelas. No seu entender essa "localização do conteúdo cognitivo da ciência está equivocada"sin. São os exemplares, enquanto padrões de solução de problema, que norteiam o jogo da ciência e não as regras.

Os cientistas desenvolvem suas pesquisas tendo por base esses exemplares, ou seja, eles resolvem os quebra-cabeças da ciência normal, vendo-os como similares a soluções anteriores. Assim, por procederem dessa maneira, os cientistas não precisam recorrer constantemente às regras. Diz Kuhn: "Os cientistas resolvem quebra-cabeças modelando-os de acordo com soluções anteriores, frequentemente com um recurso mínimo a generalizações simbólicas"32. $\mathbb{E}$, usualmente, nem questionam, nem debatem sobre o que torna um exemplar legitimo, pois, nem a questão e, tampouco a resposta, se mostram relevantes para suas pesquisas. Com isto Kuhn quer dizer que o paradigma é anterior às próprias regras para a pesquisa de ciência normal e é mais impositivo e completo que estas, que podem ser abstraídas dele.

Olhando-se o próprio treinamento que os cientistas recebem durante sua formação, fica evidente que eles não aprendem conceitos, leis e teorias de "forma abstrata e isolada", mas sim no âmbito de uma unidade histórica e pedagógica, na qual esses elementos da atividade cognitiva são apresentados juntamente com suas aplicações e por meio delas ${ }^{33}$. Deste modo, o aprendizado de uma teoria depende do estudo de suas aplicações, incluindo a prática de solução de problemas ${ }^{34}$. Kulhn procura evidenciar assim, que na formação do cientista há um "conhecimento tácito", que ocorre

\footnotetext{
${ }^{27}$ KUHN, T. A Estrutura das revoluções científicas. São Paulo: Editora Perspectiva, 1975 p. 66 ${ }^{28} \mathrm{KUHN}$, T. A Estrutura das revoluçoes científicas. São Paulo: Editora Perspectiva, 1975 p. 66

${ }^{29}$ KUHN, T. A Estrutura das revoluçōes científicas. São Paulo: Editora Perspectiva, 1975, p. 227-232

${ }^{30}$ KUHN, T. A Estrutura das revolucôes científicas. São Paulo: Editora Perspectiva, 1975, p. 232

${ }^{31}$ KUHN, T. A Estrutura das revoluçōes científicas. São Paulo: Editora Perspectiva, 1975, p. 233

${ }^{32}$ KUHN, T. A Estrutura das revolucoes científicas. São Paulo: Editora Perspectiva, 1975, p. 235

${ }^{33}$ KUHN, T. A Estrutura das revoluçoes científicas. São Paulo: Editora Perspectiva, 1975, p. 71

${ }^{34}$ KUHN, T. A Estrutura das revoluçōes científicas. São Paulo: Editora Perspectiva, 1975, p. 71
} 
por meio da prática, ou mellhor, no fazer ciência, e não por meio das regras para fazê-la, muito embora estas estejam pressupostas.

Esse processo de aprendizagem acompanha o cientista durante toda a sua formação e na medida em que ele atinge níveis mais altos de qualificação profissional os problemas que enfrenta tornam-se mais complexos e diminuem os precedentes que orientam seus estudos. Mas, isto não significa dizer que suas pesquisas não são orientadas por paradigmas e que as regras foram eliminadas desse processo, pelo contrário, os problemas que procura solucionar "continuam a moldar-se rigorosamente de acordo com realizações cientificas anteriores, o mesmo acontecendo com os problemas que normalmente o ocuparão durante sua carreira científica posterior, levada a cabo independentemente"35. Há assim, "regras" implícitas que moldam o trabalho dos cientistas na busca de solução para os problemas. A própria habilidade que ele demonstra ter ao desenvolver essa tarefa nos possibilita perceber que aprendeu os fundamentos de seu campo de estudo, os problemas e os métodos legítimos.

Mas, o processo de solução de problemas modelando soluções e tendo as regras como pressuposto não deve ser visto, como mera reprodução de uim padrão, pois o paradigma dificilmente é passível de reprodução ${ }^{36}$. O cientista ao enfrentar um problema de ciência normal, formula suas hipóteses ou conjecturas tendo por referência as "regulamentações" pressupostas e as soluções padrão. Tais hipóteses, conforme nos esclarece Kulhn, são "enunciados das conjecturas de um individuo acerca da maneira apropriada de ligar seu problema de pesquisa ao corpo do conhecimento científico aceito" ${ }^{37}$ A etapa seguinte de sua pesquisa consistirá no teste da conjectura ou hipótese. Se esta passar nos testes, o cientista resolveu o quebra-cabeça com o qual estava empenhado (p.9).

É importante notar que os testes, tal como Kuhn os concebe, não são dirigidos ao paradigma ou mais precisamente, as leis e teorias que ele comporta. A atividade de resolução de quebra-cabeças supõe que a teoria é válida, por isto não são testadas nem no sentido de se buscar confirmações, nem no sentido de refutá-las. Assim, o que é objeto de avaliação são as aplicações da teoria, ou seja, as soluções conjecturais propostas pelos cientistas aos quebra-cabeças. Se estas soluções não passarem nos testes, é somente a habilidade do cientista que é contestada e não o paradigma. Diz Kuhn: "Em suma, conquanto ocorram com frequência na ciência normal, esses testes são de um gênero peculiar, pois na análise final, é o cientista e não a teoria vigente que se põe em teste.

Fica evidente que Kulhn considera que no âmbito da ciência normal não há o tịpo de testes que a tradição epistemológica consolidou cujo propósito é submeter a prova uma teoria no sentido de confirmá-la ou refutá-la, por meio de experimentos. Os testes que ele advoga põem em xeque a habilidade do cientista em solucionar os quebracabeças e não as leis e teorias, que compõem o paradigma. Assim, o cientista quando enfrenta um problema de ciência normal deve ter como pressuposto as teorias e leis como regra de seu jogo. O seu objetivo é a resolução do quebra-cabeça e a teoria se mostra indispensável não apenas para defini-lo como um problema de ciência normal, como também, para garantir que o problema tem uma solução e, estando essas condições asseguradas, só depende da habilidade do cientista encontrar esta solução.

\section{Considerações finais}

\footnotetext{
${ }^{35}$ KUHN, T. A Estrutura das revoluções científicas. São Paulo: Editora Perspectiva, 1975, p. 72

${ }^{36}$ KUHN, T. A Estrutura das revoluções científicas. São Paulo: Editora Perspectiva, 1975, p. 43

${ }^{37}$ KUHN, T. "Lógica da descoberta ou psicologia da pesquisa?". In LAKATOS, I. E MUSGRAVE, A. A critica e o desenvolvimento do conhecimento. São Paulo: Editora Cultrix, 1979, p.9

${ }^{38}$ KUHN, T. "Lógica da descoberta ou psicologia da pesquisa?". In LAKATOS, I. E MUSGRAVE, A. A critica e o desenvolvimento do conhecimento. São Paulo: Editora Cultrix, 1979, p.10
} 
A abordagem de Kuhn da ciência normal, tendo como referência a analogia com o jogo de quebra-cabeças, nos possibilita perceber que ele tem uma concepção de ciência peculiar, que valoriza os problemas a serem investigados. Estes constituem verdadeiros desafios aos cientistas na medida em que há uma expectativa de solução para os mesmos. E, se presume que os cientistas com a formação que tiveram, centrada na aplicação de soluções-padrão, se tornaram hábeis em solucioná-los.

O outro aspecto, inovador de sua concepção está na forma como os cientistas solucionam os quebra-cabeças. Diferentemente da tradição que valorizou as teorias e estabeleceu regras metodológicas para obtê-las, o filósofo volta-se para a aplicação de exemplares, ou seja, para as soluções padronizadas de problemas. São estas que devem nortear a prática da ciência.

Mas, embora Kuhn priorize as soluções exemplares, ele reconhece que para a pesquisa científica se desenvolver o cientista deve pressupor todo um conjunto de regulamentações que orientam seu trabalho.

O que se pode perceber na argumentação de Kulhn, sobre a prioridade das soluções padrão (exemplares) com relação às regras, é que o tempo todo ele está lidando com duas noções distintas do termo paradigma, uma entendida como o exemplar que possibilita que os cientistas solucionem novos problemas orientados pelos padrões de solução que dispõem e a outtra, em que o paradigma, em seu sentido mais geral, aparece como pressuposto. Neste sentido, o paradigma é entendido como o "conjunto de compromissos" aos quais os cientistas aderem - que engloba as generalizações simbólicas, os modelos, os métodos, técnicas, instrumentos e os valores e se identifica com as próprias regras implícitas. O paradigma tomado como esse conjunto de pressupostos representa o pano de fundo, que os cientistas têm em conta ao desenvolverem sua pesquisa. Trata-se de uma espécie de estrutura no qual o jogo da ciência é travado. Esta estrutura é histórica, e pode mudar conforme o desenvolvimento da ciência. Mas, não é possível a solução de nenhuum quebra-cabeça da ciência normal se esta estrutura não for pressuposta.

Essa estrutura além de definir os tipos de problemas a serem solucionados pelos cientistas indica as possíveis soluções para os mesmos. Assim, sendo o cientista guiado pelos exemplares e pressupondo todo um conjunto de "regras", será capaz de conjecturar soluções para outros problemas similares. Vista desta perspectiva, a solução dos problemas não está dada previamente, ela deve ser "construída" tendo por base os parâmetros que se encontram na estrutura com a qual o cientista está comprometido. $\mathbb{E}$ se ele fracassa nesta empreitada, é apenas a sua conjectura que é refutada, devido a sua falta de treino para lidar com os problemas que enfrenta. Toda a estrutura que o orienta, permanece.

Fica evidente assim, o caráter da nova investigação científica, preconizada por Kuhn, que tem por foco principal o tipo de problemas que os cientistas enfrentam e a aplicação dos padrões de solução que dispõe, pressupondo as "regras" que internalizou no decorrer de sua formação. 


\section{Referências}

ABRANTES, P.C. Método e ciência: uma abordagem filosófica. 2o ed. Belo Horizonte/MG. : Fino traço, 2014.

HUENE-HOYNINGEN, P. Reconstructing scientific revolutions. Chicago e London: The University of Chicago press, 1993.

KUHN, T. A Estrutura das revoluções científicas. São Paulo: Editora Perspectiva, 1975.

Lógica da descoberta ou psicologia da pesquisa?. In LAKATOS, I. E MUSGRAVE, A. A crítica e o desenvolvimento do conhecimento. São Paulo: Editora Cultrix, 1979.

A tensão essencial. São Paulo: Ed. da Unesp, 2011.

POPPER, K. A lógica da pesquisa científica. São Paulo: Cultrix, 1972.

. Conjecturas e refutações. 2a ed. Brasília: Ed. da Universidade de Brasília, 1982.

- Lógica das Ciências sociais. Rio de Janeiro: Tempo brasileiro, 1978.

RANSANZ, A.R.P. Kuhn y el cambio científico. 1a ed. México: Fondo de Cultura económica, 1999.

Doutora em Filosofia (Unicamp, 2000) Professora do Departamento de Filosofia (UFPA)

Docente do PPG Filosofia - ÜPA

E-mail: elizabethadias28@gmail.com 